\title{
Accessibility of Low-cost Insulin From Illegitimate Internet Pharmacies: Cross-sectional Study
}

Benjamin Penley ${ }^{1}$, PharmD; Lana Minshew ${ }^{2}$, PhD; Hui-Han Chen ${ }^{1}$, MHS; Stephen Eckel ${ }^{1}$, MHA, PharmD; Sachiko Ozawa $^{1,3}$, MHS, PhD

${ }^{1}$ Division of Practice Advancement and Clinical Education, Eshelman School of Pharmacy, University of North Carolina at Chapel Hill, Chapel Hill, NC, United States

${ }^{2}$ Center for Innovative Pharmacy Education and Research, Eshelman School of Pharmacy, University of North Carolina at Chapel Hill, Chapel Hill, $\mathrm{NC}$, United States

${ }^{3}$ Department of Maternal and Child Health, Gillings School of Global Public Health, University of North Carolina at Chapel Hill, Chapel Hill, NC, United States

\section{Corresponding Author:}

Sachiko Ozawa, MHS, PhD

Division of Practice Advancement and Clinical Education

Eshelman School of Pharmacy

University of North Carolina at Chapel Hill

CB \#7574 Beard Hall 115G

Eshelman School of Pharmacy

Chapel Hill, NC, 27599

United States

Phone: 19199662626

Email: ozawa@unc.edu

\section{Abstract}

Background: There is much public debate regarding the high cost of insulin. With 1-in-4 patients in the United States with type 1 diabetes reporting difficulties affording insulin, there is concern that some of these patients might look for cost savings on the internet, unaware that $96 \%$ of internet pharmacies are illegitimate. Patients who purchase insulin from illegitimate internet pharmacies remove themselves from traditional health care systems that ensure safe, quality-assured, and effective medication use.

Objective: This study aims to determine the accessibility of Humalog and NovoLog insulin from internet pharmacies and characterize how these sites approached patient safety, and priced as well as marketed their products.

Methods: From September to December 2019, we queried the phrases buy insulin online, buy Humalog online, and buy NovoLog online in common search engines. The first 100 search results from Google and Bing, and the first 50 search results from Yahoo! and DuckDuckGo were screened. Websites were included if they claimed to sell Humalog or NovoLog insulin, were active, free access, in the English language, and had a unique URL. The legitimacy of websites was classified using LegitScript. Safety and marketing characteristics were compared across the legitimacy of internet pharmacies. Internet pharmacy prices were compared with the prices offered through brick-and-mortar pharmacies using GoodRx.

Results: We found that $59 \%(\mathrm{n}=29)$ of the 49 internet pharmacies in our analysis were illegitimate, whereas only $14 \%(\mathrm{n}=7)$ were legitimate and 27\% ( $\mathrm{n}=13)$ were unclassified. Across illegitimate internet pharmacies, Humalog and NovoLog insulin were 2 to 5 times cheaper as compared with both legitimate internet pharmacies and brick-and-mortar stores. Risks associated with the use of illegitimate internet pharmacies by American consumers were evident: 57\% (8/14) did not require a prescription, 43\% (6/14) did not display medication information or warnings, and only $21 \%(3 / 14)$ offered access to purported pharmacists. This included 9 rogue internet pharmacies that sold Humalog and NovoLog insulin within the United States, where 11\% (1/9) required a prescription, $11 \%$ (1/9) placed quantity limits per purchase, and none offered pharmacist services. Rogue internet pharmacies often offered bulk discounts $(11 / 18,61 \%)$, assured privacy $(14 / 18,78 \%)$, and promoted other products alongside insulin $(13 / 18$, $72 \%)$. The marketing language of illegitimate internet pharmacies appealed more to quality, safety, and customer service as compared with legitimate sites.

Conclusions: The ease of access to low-cost insulin through illegitimate internet pharmacies calls for urgent attention. Illegitimate internet pharmacies place patients at risk of poor-quality medications and subpar pharmacy services, resulting in adverse events 
and poor diabetes control. A multifaceted approach is needed to close illegitimate internet pharmacies through legal and regulatory measures, develop better search engine filters, raise public awareness of the dangers of illegitimate internet pharmacies, and address the high costs of insulin.

(J Med Internet Res 2022;24(2):e25855) doi: 10.2196/25855

\section{KEYWORDS}

insulin; diabetes; internet; online; pharmacy; medication; cost

\section{Introduction}

\section{Access to Insulin}

For patients with type 1 or type 2 advanced diabetes, insulin is the cornerstone of therapy. Furthermore, 1 in 10 Americans (around 34.2 million people) have diabetes, with nearly 1.6 million living with type 1 diabetes [1]. Patients with type 1 diabetes cannot produce endogenous insulin and thus require treatment with exogenous insulin. For patients living with type 2 diabetes, insulin is often required if adequate glycemic control is not maintained with lifestyle modifications and noninsulin medications. In patients who require insulin, regulation of blood glucose is tantamount to disease control; if uncontrolled, it can result in acute, life-threatening conditions of diabetic ketoacidosis or severe hypoglycemia, as well as chronic but still life-threatening complications such as cardiovascular disease, nephropathies, retinopathies, and neuropathies [2]. These complications can result in-among other outcomes - dialysis-dependence, blindness, amputations, serious quality-of-life reductions, and death [2].

Increasingly, rising costs unique to the US market have hindered access to insulin for patients [3]. Despite legislative initiatives to control prescription drug costs, high insulin costs in the United States persist, with list prices of insulin tripling between 2003 and 2013 [3]. Although insulin was first used as a medication in 1922, the insulin market remains dominated by branded products, with no actual generic drug approved. This is important as generic competition has been shown to decrease medicine prices by $60 \%$ on average, when 3 or more manufacturers that are generic are in the market [4]. High costs are associated with all insulin types, but rapid-acting insulin analogs such as Humalog (insulin lispro) and NovoLog (insulin aspart) are among the highest priced [3]. Humalog's list price, for example, continued to increase after 2014 from US \$391 to nearly US $\$ 600$ in 2017-a list price increase similar to that of its competitor NovoLog. It is worth noting that net prices remained relatively stable for Humalog and NovoLog during that time frame, meaning that an increase in costs was primarily offset by discounts made available [5]. Regardless, high list prices have a direct impact on patients; in 2019, 1 in 4 patients in the United States with type 1 diabetes reported difficulties affording their medication [6]. Patients such as these are often led to make difficult decisions. More than 1 in 4 patients in the United States with type 1 diabetes reported rationing their insulin in 2019 [7]. Patients who struggle to access insulin from traditional methods, namely brick-and-mortar pharmacies, might look for alternative, lower-cost methods, such as purchasing insulin from friends, across borders, or from illegitimate internet pharmacies $[8,9]$.

\section{Growth of Internet Pharmacies}

Internet pharmacies are a popular destination for the purchase of prescription drugs, with 30,000 to 35,000 internet pharmacies accessible in 2016 [10]. Internet pharmacies are defined by whether they operate as legitimate pharmacies or whether they are illegitimate and in violation of US pharmacy laws and practice standards [11]. It has been reported that $96 \%$ of all accessible internet pharmacies are illegitimate [10]. According to the World Health Organization, more than $50 \%$ of medications acquired from internet pharmacies that do not advertise their physical location (a common characteristic of illegitimate internet pharmacies) are counterfeit or substandard [12]. The dangers associated with illegitimate internet pharmacies have led to the implementation of rules and regulations to ensure safe internet pharmacy use. For example, several states in the United States require internet pharmacies to be accredited with the National Association of Boards of Pharmacy (NABP) to receive licensure [13]. However, the enforcement of such rules and regulations is complicated by an intricate e-commerce environment composed of numerous, often international, stakeholders [11]. The complexity and anonymity of e-commerce allows illegitimate internet pharmacies to avoid detection, and even when detected, reopen operations under new web addresses [14]. Given the evasiveness and high prevalence of illegitimate internet pharmacies, there is concern that patients purchasing medications on the internet might be subject to low-quality products, which could result in the development of dangerous adverse effects, especially for high-risk medications such as insulin.

Beyond concerns related to medication quality, there is also concern regarding the lack of services offered by illegitimate internet pharmacies [15]. In choosing illegitimate internet pharmacies, patients opt out of medication counseling, monitoring, and drug-drug interactions checking that pharmacists and other health care professionals provide to ensure proper medication use [16]. The use of these resources is well documented to improve patient outcomes [17]. Insufficient safety measures could also be further exacerbated by marketing methods that illegitimate internet pharmacies use to attract consumers. Although it has been shown that patients using illegitimate internet pharmacies are at greater risk of developing adverse effects from treatment, there is a lack of current data on how illegitimate internet pharmacies approach patient safety and the marketing methods they use, particularly for high-risk medications [18].

\section{Objective}

The accessibility of rapid-acting insulins from illegitimate internet pharmacies could pose a threat to patient safety. We 
investigated the availability of Humalog and NovoLog insulin from internet pharmacies through common search engines and documented the website's safety and marketing characteristics, as well as the costs of Humalog and NovoLog insulin.

\section{Methods}

\section{Overview}

Humalog and NovoLog were chosen for our analysis because of their relatively recent approval by the US Food and Drug Administration (FDA), high list prices, and their outsized role in the discussion of medication pricing in the United States [3]. Website screening was conducted from September to December 2019 using 4 search engines (Google, Bing, Yahoo!, and DuckDuckGo) with the phrases buy insulin online, buy Humalog online, and buy NovoLog online. For each search phrase, the first 100 results from Google and Bing and the first 50 of Yahoo! and DuckDuckGo were screened. Google, Bing, and Yahoo! were chosen for their widespread use in the United States. In addition, DuckDuckGo was searched because of its emphasis on user privacy. Websites were included if they claimed to sell Humalog or NovoLog insulin, were active, free access, in the English language, and had a unique URL. Websites selling Humalog or NovoLog insulin that were accessed from search engine results through a landing page were included. Screenshots were taken of each website for records.

The legitimacy of websites was assessed using LegitScript, which classifies pharmacies according to licensure or registration in affiliated jurisdictions, sale of controlled substances, previous discipline, requirement of valid prescription, protection of privacy, patient services offered, transparency, and domain name registration [19]. LegitScript was chosen to assess internet pharmacy legitimacy because of the breadth of internet pharmacies that it monitors $(81,000+)$ and its partnerships with private (eg, Google, Amazon, Facebook) and governmental agencies (eg, FDA). The websites in this analysis were classified as (1) illegitimate, subclassified as (1a) rogue-these merchants engage in illegal, unsafe, or misleading activities such as selling prescription drugs without a prescription and (1b) unapproved-there is some problem with regulatory compliance or risk, but it is typically less egregious than rogue or (2) legitimate-these merchants are registered with a LegitScript certification program and have passed LegitScript certification criteria or (3) unclassified-no information was available from LegitScript.

The average monthly traffic to website domains defined as unique visits from any country was obtained from SimilarWeb [20]. This website aggregates information on website traffic from a variety of sources. We compared website traffic with the legitimacy of internet pharmacies. The IP addresses of internet pharmacies were examined using IP2location, which retrieves geographic information based on IP addresses [21]. IP address locations were compared with their listed locations.

\section{Costs}

Costs of Humalog and NovoLog $100 \mathrm{IU} / \mathrm{mL}$ insulin at the most frequently sold dosage forms (ie, $1 \times 10-\mathrm{mL}$ vials, $5 \times 3-\mathrm{mL}$ pens, $5 \times 3-\mathrm{mL}$ cartridges) were collected from a subset of internet pharmacies offering to ship within the United States. Prices per $\mathrm{mL}$ of $100 \mathrm{IU} / \mathrm{mL}$ Humalog and NovoLog insulin for vials, pens, and cartridges were calculated. The shipping costs and bulk discounts were not considered in the cost calculations. Internet pharmacy prices were compared with prices offered through GoodRx, a drug coupon website. GoodRx prices are representative of out-of-pocket prices that uninsured US patients might pay at brick-and-mortar stores. Average prices at brick-and-mortar stores were obtained from GoodRx on April 30, 2020. Costs were averaged by legitimacy of internet pharmacies among websites selling Humalog and NovoLog pens that offered US shipping.

\section{Marketing}

Marketing characteristics were selected based on previous literature, and the analysis focused on internet pharmacies classified by LegitScript $[11,16,22,23]$. Marketing characteristics were compared across the legitimacy of internet pharmacies. Cost-related marketing characteristics included whether internet pharmacies offered bulk discounts or promo codes. Promotional marketing characteristics included whether internet pharmacies displayed specific medication advertisements pertaining to any form of insulin, advertisements for other products on the page advertising Humalog or NovoLog insulin, or customer testimonies. Marketing characteristics appealing to customer service and general reputability included whether internet pharmacies displayed a phone number, offered the assistance of an associate, or claimed pharmacy registration in some form (eg, Canadian International Pharmacy Association, International Pharmacy Association of British Columbia, or PharmacyChecker [24]). Additional marketing characteristics included whether internet pharmacies offered privacy assurances (eg, discrete packaging or protection of health- or billing-related information) or offered shipping within the United States.

We qualitatively analyzed the website marketing language by collecting texts from the homepages of all included internet pharmacies. After initially reading through the texts to identify the most common marketing language, we selected and defined 6 characteristics. Texts were then screened to assess whether these six characteristics were discussed: (1) quality, (2) safety, (3) customer service, (4) reputability, (5) affordability, and (6) convenience. Quotes representative of each characteristic were collected by legitimacy of internet pharmacies.

\section{Safety}

Safety characteristics were selected based on previous literature and focused on internet pharmacies classified by LegitScript $[11,16,22,23]$. To allow a specific focus on US pharmacies, or those that should be compliant with US laws and regulations, safety characteristics were analyzed only for internet pharmacies that offered shipping within the United States. Safety characteristics were compared across the legitimacy of internet pharmacies. Basic pharmacy-related characteristics included the requirement of a prescription and controls on the amount of Humalog or NovoLog insulin that could be ordered (eg, restricting patients to a 90-day supply or the quantity listed on their prescription). Characteristics related to pharmacy services included whether there was an offer to speak with a pharmacist and whether medication information and drug-related warnings 
and precautions were displayed on the product page. Characteristics related to location included whether the pharmacy listed a physical location and the website location listed matched the country of the IP address.

\section{Results}

\section{Overview}

We screened 300 websites and identified a total of 49 internet pharmacies that claimed to sell Humalog or NovoLog insulin. Of the internet pharmacies, LegitScript classified 59\% (29/49) as illegitimate, including $37 \%(18 / 49)$ as rogue and $22 \%(11 / 49)$ as unapproved, whereas $14 \%$ (7/49) were legitimate and $27 \%$ $(13 / 49)$ were unclassified. The listed locations of these internet pharmacies differed, with $41 \%$ (12/29, all rogue sites) of illegitimate internet pharmacies advertising no location. Of the 29 illegitimate internet pharmacies, 52\% (15, 4 rogue and 11 unapproved sites) advertised a Canadian location. The remaining illegitimate internet pharmacies claimed to be located in Great Britain $(1 / 29,3 \%)$ or in Europe $(1 / 29,3 \%)$. No illegitimate internet pharmacies advertised a US location. For legitimate internet pharmacies, $43 \%$ (3/7) advertised locations in the United States, 29\% (2/7) in Australia, 14\% (1/7) in Canada, and 14\% $(1 / 7)$ in India. The majority $(4 / 7,57 \%)$ of legitimate internet pharmacies' physical locations listed on their websites matched those of their server locations. In contrast, physical and server locations matched only $27 \%$ (3/11) of the time among unapproved internet pharmacies. None of the physical and server locations matched among the 18 rogue internet pharmacies.

Traffic to internet pharmacies, as determined by SimilarWeb [20], differed depending on the legitimacy of internet pharmacies. Although illegitimate internet pharmacies were the most abundant in the search results, unique monthly visits to each site were comparatively lower for illegitimate internet pharmacies $(0-250,000)$ than to legitimate internet pharmacies (5000-63.6 million). The 3 US-based legitimate internet pharmacies received the highest volumes of unique monthly traffic reported at 63.6 million (Costco), 40.35 million (CVS), and 1.17 million (Healthwarehouse) visits per month [25-27].

\section{Costs}

The costs of Humalog and NovoLog insulin vials, pens, and cartridges were recorded only for internet pharmacies shipping within the United States $(n=22)$. The most commonly sold volume and strength of the insulin vials were $10 \mathrm{~mL}$ at 100 IU/mL. Humalog and NovoLog insulin $3 \mathrm{~mL}$ pens and $3 \mathrm{~mL}$ cartridges were most often sold in packages containing a quantity of 5, which is in alignment with product packaging available from brick-and-mortar pharmacies. The cost per $\mathrm{mL}$ of $100 \mathrm{IU} / \mathrm{mL}$ insulin varied depending on the legitimacy of the internet pharmacies. For rogue internet pharmacies, the average costs of insulin varied depending on dosage forms: Humalog vials cost US $\$ 11.30(n=1)$, Humalog pens cost US $\$ 7.84(n=4)$, and Humalog cartridges cost US $\$ 10.04(n=4)$, whereas NovoLog vials cost US $\$ 5.90(n=2)$, NovoLog pens cost US $\$ 8.47(n=7)$, and NovoLog cartridges cost US $\$ 8.00(n=3)$. Costs were similarly low in unapproved and unclassified internet pharmacies.

For legitimate internet pharmacies, the average costs of insulin (without insurance) were two- to five-fold higher: Humalog vials cost US \$31.51 $(n=2)$ and Humalog pens cost US \$38.89 $(n=2)$, whereas Humalog cartridges were not available; meanwhile NovoLog vials cost US $\$ 32.77(n=2)$, NovoLog pens cost US $\$ 40.77(n=2)$, and NovoLog cartridges cost US $\$ 38.47(n=2)$. Compared with illegitimate pharmacies, GoodRx costs-representative of average costs at brick-and-mortar pharmacies-were also approximately 2 to 5 times more expensive. However, compared with the cost of legitimate internet pharmacies for uninsured patients excluding shipping costs, GoodRx prices were marginally cheaper: Humalog vials cost US \$17.22, Humalog pens cost US \$21.83, and Humalog cartridges cost US \$34.13, whereas NovoLog vials cost US \$29.38, NovoLog pens cost US \$37.31, and NovoLog cartridges cost US $\$ 35.90$. The difference in costs per $\mathrm{mL}$ of Humalog and NovoLog insulin pens (the most common dosage form in our analysis) depending on the source is depicted in Figure 1.

Figure 1. Costs of Humalog and NovoLog insulin pens available in the United States on the internet and at brick-and-mortar stores.

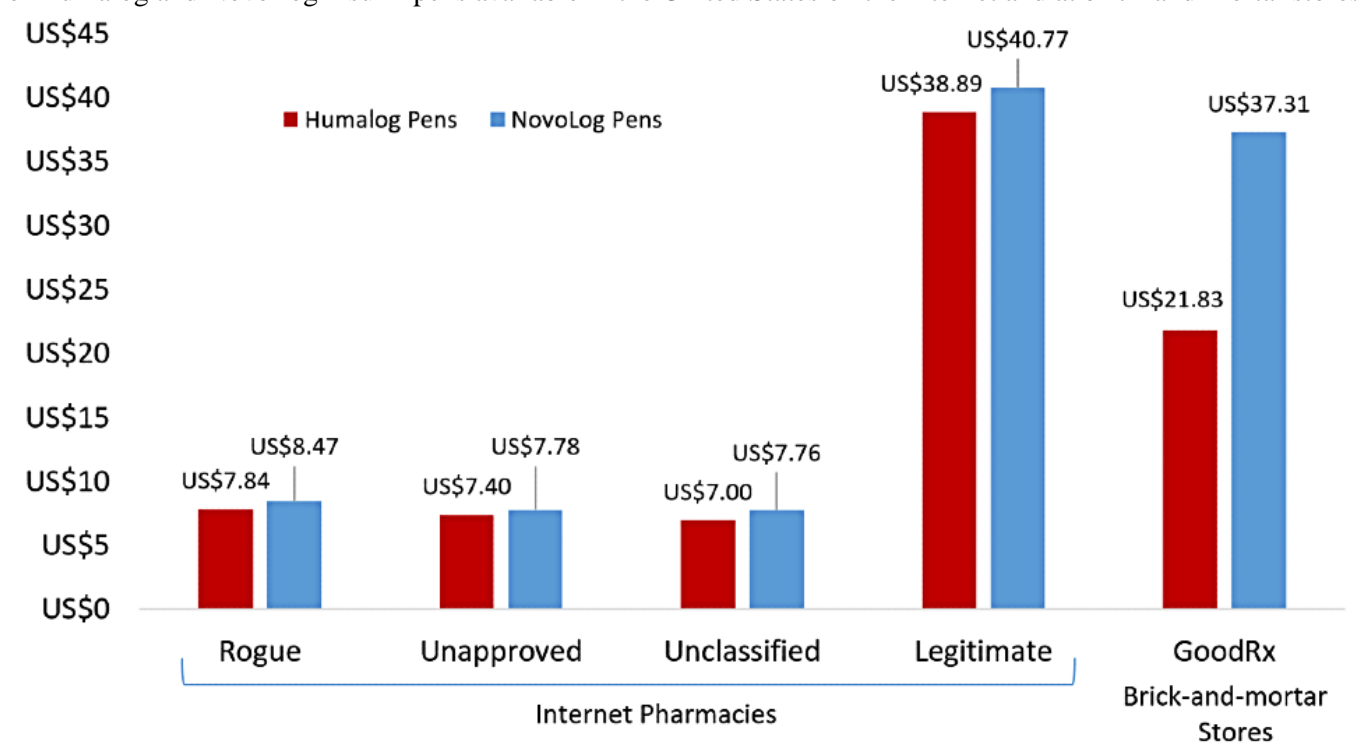




\section{Marketing}

The marketing characteristics of internet pharmacies selling Humalog and NovoLog insulin and classified by LegitScript $(\mathrm{N}=36)$ are described in Table 1. Rogue internet pharmacies differed from unapproved and legitimate internet pharmacies across several characteristics. More often, rogue internet pharmacies offered bulk discounts $(11 / 18,61 \%)$, assured privacy $(14 / 18,78 \%)$, and promoted other products on the Humalog or
NovoLog insulin product pages $(13 / 18,72 \%)$. Although rogue internet pharmacies offered some form of contact through email or chat functions, most sites did not offer a phone number $(11 / 18,61 \%)$. Both legitimate $(n=7)$ and unapproved $(n=11)$ internet pharmacies shared similar characteristics, where few offered bulk discounts (2/7, 29\% legitimate; 2/11, 18\% unapproved), all displayed a phone number $(18 / 18,100 \%)$, and most touted registration or made accreditation claims $(6 / 7,86 \%$ legitimate; 10/11, 91\% unapproved).

Table 1. Marketing characteristics of internet pharmacies selling Humalog or NovoLog ${ }^{\mathrm{a}}$.

\begin{tabular}{|c|c|c|c|c|c|c|c|c|c|}
\hline \multirow[t]{2}{*}{ Characteristics } & \multicolumn{3}{|c|}{ Rogue (n=18), n (\%) } & \multicolumn{3}{|c|}{ Unapproved $(\mathrm{n}=11), \mathrm{n}(\%)$} & \multicolumn{3}{|c|}{ Legitimate $(\mathrm{n}=7), \mathrm{n}(\%)$} \\
\hline & Yes & No & Not reported & Yes & No & Not reported & Yes & No & Not reported \\
\hline US shipping of insulin & $9(50)$ & $9(50)$ & $0(0)$ & $5(45)$ & $6(55)$ & $0(0)$ & $3(43)$ & $4(57)$ & $0(0)$ \\
\hline Bulk discounts & $11(61)$ & $5(28)$ & $2(11)$ & $2(18)$ & $8(73)$ & $1(9)$ & $2(29)$ & $5(71)$ & $0(0)$ \\
\hline Coupons & $9(50)$ & $8(44)$ & $1(6)$ & $2(18)$ & $9(82)$ & $0(0)$ & $4(57)$ & $3(43)$ & $0(0)$ \\
\hline Registration claims & $8(44)$ & $10(56)$ & $0(0)$ & $10(91)$ & $1(9)$ & $0(0)$ & $6(86)$ & $1(14)$ & $0(0)$ \\
\hline Privacy assurances & $14(78)$ & $4(22)$ & $0(0)$ & $8(73)$ & $3(27)$ & $0(0)$ & $1(14)$ & $6(86)$ & $0(0)$ \\
\hline Customer testimonies & $10(56)$ & $8(44)$ & $0(0)$ & $7(64)$ & $4(36)$ & $0(0)$ & $3(43)$ & $4(57)$ & $0(0)$ \\
\hline Offer to speak with associate & $18(100)$ & $0(0)$ & $0(0)$ & $9(82)$ & $2(18)$ & $0(0)$ & $6(86)$ & $1(14)$ & $0(0)$ \\
\hline Phone number & $7(39)$ & $11(61)$ & $0(0)$ & $11(100)$ & $0(0)$ & $0(0)$ & $7(100)$ & $0(0)$ & $0(0)$ \\
\hline Insulin-specific advertisements & $0(0)$ & $18(100)$ & $0(0)$ & $3(27)$ & $8(73)$ & $0(0)$ & $0(0)$ & $7(100)$ & $0(0)$ \\
\hline $\begin{array}{l}\text { Advertisements for other products on } \\
\text { page selling insulin }\end{array}$ & $13(72)$ & $5(28)$ & $0(0)$ & $1(9)$ & $10(91)$ & $0(0)$ & $4(57)$ & $1(14)$ & $2(29)$ \\
\hline
\end{tabular}

${ }^{\mathrm{a}}$ Illustrates marketing characteristics of 36 websites selling Humalog or NovoLog. This table does not include 13 internet pharmacies selling Humalog or NovoLog insulin that were not classified by LegitScript.

Marketing language from website homepages differed according to the legitimacy of internet pharmacies, particularly for quality, safety, and customer service. Although 83\% (24/29) of illegitimate internet pharmacies appealed to quality, only $29 \%$ (2/7) of legitimate internet pharmacies used language that suggest the quality of medication or services. Marketing language appealing to safety $(19 / 29,66 \%$ illegitimate vs $1 / 7$, $14 \%$ legitimate) and customer service (24/29, $83 \%$ vs $4 / 7,57 \%$ ) were also more common among illegitimate internet pharmacies. The frequency of use of marketing language was similar among reputability $(16 / 29,55 \%$ vs $4 / 7,57 \%)$, affordability $(24 / 29$, $83 \%$ vs $5 / 7,71 \%$ ), and convenience $(22 / 29,76 \%$ vs $5 / 7,71 \%$ ).
Differences in marketing language are also demonstrated through the selection of quotes in Table 2. The marketing language of illegitimate internet pharmacies tended to communicate a sense of urgency to purchase products and strongly emphasized the merits of the pharmacy. For example, one quote from an illegitimate internet pharmacy appealed to reputation, affordability, and safety:
If you are looking to buy your prescription drugs in Canada, through a reputable international or online Canadian pharmacy, [our online pharmacy] provides you access to a trusted source of affordable and safe prescription drugs. [Illegitimate pharmacy] 
Table 2. Types of marketing language used on the home pages of internet pharmacies.

\begin{tabular}{|c|c|c|c|c|c|}
\hline \multirow[t]{2}{*}{ Characteristics } & \multirow[t]{2}{*}{ Description } & \multicolumn{2}{|c|}{ Illegitimate $(n=29)$} & \multicolumn{2}{|c|}{ Legitimate $(\mathrm{n}=7)$} \\
\hline & & $\begin{array}{l}\text { Values, } \mathrm{n} \\
(\%)\end{array}$ & Selected quote ${ }^{\mathrm{a}}$ & $\begin{array}{l}\text { Values, } \mathrm{n} \\
(\%)\end{array}$ & Selected quote \\
\hline Quality & $\begin{array}{l}\text { Language suggesting quality of } \\
\text { medication or services }\end{array}$ & $24(83)$ & $\begin{array}{l}\text { "We guarantee that all [medications] } \\
\text { for sale on this site are } 100 \% \text { gen- } \\
\text { uine and extremely powerful." }\end{array}$ & $2(29)$ & "[We] offer you quality care..." \\
\hline Safety & $\begin{array}{l}\text { Language explicitly referring to } \\
\text { the safety of medication products, } \\
\text { internet ordering platform, or other } \\
\text { services }\end{array}$ & $19(66)$ & $\begin{array}{l}\text { "When it comes to your health, we } \\
\text { know that safety is your number one } \\
\text { concern. It's ours too." }\end{array}$ & $1(14)$ & $\begin{array}{l}\text { "Besides delivering medicines } \\
\text { at your doorstep, we...help } \\
\text { people use their medicines ef- } \\
\text { fectively and safely." }\end{array}$ \\
\hline Customer service & $\begin{array}{l}\text { Language suggesting availability } \\
\text { of staff to answer questions or } \\
\text { remedy problems }\end{array}$ & $24(83)$ & $\begin{array}{l}\text { "24/7 customer support (we are al- } \\
\text { ways at your disposal!)." }\end{array}$ & $4(57)$ & $\begin{array}{l}\text { "Customer service: get answers } \\
\text { to your questions." }\end{array}$ \\
\hline Reputability & $\begin{array}{l}\text { Language suggesting renown in } \\
\text { selling or accreditation to sell pre- } \\
\text { scription drugs }\end{array}$ & $16(55)$ & $\begin{array}{l}\text { "[Our pharmacy] has a great reputa- } \\
\text { tion serving the community for } 47 \\
\text { years and counting." }\end{array}$ & $4(57)$ & $\begin{array}{l}\text { "Accredited and Certified in all } \\
50 \text { states." }\end{array}$ \\
\hline Affordability & $\begin{array}{l}\text { Language suggesting discounts or } \\
\text { cheap prescription drugs }\end{array}$ & $24(83)$ & $\begin{array}{l}\text { "[We] provide the same insulin } \\
\text { that's available in the US except our } \\
\text { prices are much lower, and we pass } \\
\text { on the savings to you." }\end{array}$ & $5(71)$ & $\begin{array}{l}\text { "At [our pharmacy], you can } \\
\text { buy health products and } \\
\text { medicines online at best dis- } \\
\text { counts." }\end{array}$ \\
\hline Convenience & $\begin{array}{l}\text { Language suggesting ease of inter- } \\
\text { net pharmacy use or prescription } \\
\text { drug purchase; fast delivery or } \\
\text { services that allow for time savings }\end{array}$ & $22(76)$ & $\begin{array}{l}\text { "The process of payment through } \\
\text { Bitcoin is simple. You need to go } \\
\text { through only a few steps to quickly } \\
\text { confirm and complete your order." }\end{array}$ & $5(71)$ & $\begin{array}{l}\text { "You get the convenience of } \\
\text { online shopping combined with } \\
\text { the support and guidance of our } \\
\text { dedicated team." }\end{array}$ \\
\hline
\end{tabular}

${ }^{\mathrm{a}}$ Quotes were taken directly from internet pharmacy websites.

\section{Safety}

The safety characteristics of internet pharmacies selling Humalog and NovoLog insulin within the United States and classified by LegitScript $(\mathrm{N}=17)$ are described in Table 3. Overall, illegitimate internet pharmacies revealed poor patient safety records: $57 \%(8 / 14)$ did not require a prescription, $43 \%$ $(6 / 14)$ did not display medication information or warnings, and only $21 \%$ (3/14) offered access to pharmacists. Rogue internet pharmacies differed from legitimate internet pharmacies more substantially than unapproved internet pharmacies in terms of patient safety. Rogue internet pharmacies seldom required a prescription $(1 / 9,11 \%)$ or placed quantity limits on the amount of medication that could be ordered $(1 / 9,11 \%)$, and none offered pharmacist services $(0 / 9,0 \%)$. Unapproved internet pharmacies uniformly claimed to require a prescription $(5 / 5,100 \%)$ and placed quantity limits $(5 / 5,100 \%)$, and some sites offered pharmacist services $(3 / 5,60 \%)$. Drug-related information and warnings were not uniformly displayed for both rogue and unapproved internet pharmacies.

Data were unavailable for one legitimate internet pharmacy regarding whether pharmacist services were offered (where member registration was required). Not all legitimate internet pharmacies were accredited through the NABP because of geography. However, legitimate internet pharmacies required or displayed characteristics consistent with best internet pharmacy communication practices, such as requiring pharmacists to offer individual, meaningful consultations [13]. 
Table 3. Safety characteristics of internet pharmacies selling Humalog or NovoLog insulin in the United States.

\begin{tabular}{|c|c|c|c|c|c|c|c|c|c|}
\hline \multirow[t]{2}{*}{ Safety characteristics } & \multicolumn{3}{|c|}{ Rogue (n=9), n (\%) } & \multicolumn{3}{|c|}{ Unapproved $(\mathrm{n}=5), \mathrm{n}(\%)$} & \multicolumn{3}{|c|}{ Legitimate $(\mathrm{n}=3), \mathrm{n}(\%)$} \\
\hline & Yes & No & Not reported & Yes & No & Not reported & Yes & No & Not reported \\
\hline Prescription required & $1(11)$ & $8(89)$ & $0(0)$ & $5(100)$ & $0(0)$ & $0(0)$ & $3(100)$ & $0(0)$ & $0(0)$ \\
\hline Offer to speak with pharmacist & $0(0)$ & $9(100)$ & $0(0)$ & $3(60)$ & $2(40)$ & $0(0)$ & $2(67)$ & $0(0)$ & $1(33)^{\mathrm{a}}$ \\
\hline Medication precautions on product page & $6(67)$ & $3(33)$ & $0(0)$ & $2(40)$ & $3(60)$ & $0(0)$ & $3(100)$ & $0(0)$ & $0(0)$ \\
\hline Medication information on product page & $6(67)$ & $3(33)$ & $0(0)$ & $2(40)$ & $3(60)$ & $0(0)$ & $3(100)$ & $0(0)$ & $0(0)$ \\
\hline Quantity control & $1(11)$ & $8(89)$ & $0(0)$ & $5(100)$ & $0(0)$ & $0(0)$ & $3(100)$ & $0(0)$ & $0(0)$ \\
\hline Lists a physical location & $4(44)$ & $5(56)$ & $0(0)$ & $5(100)$ & $0(0)$ & $0(0)$ & $3(100)$ & $0(0)$ & $0(0)$ \\
\hline $\begin{array}{l}\text { Location listed on website and location of } \\
\text { server match }\end{array}$ & $0(0)$ & $9(100)$ & $0(0)$ & $2(40)$ & $3(60)$ & $0(0)$ & $3(100)$ & $0(0)$ & $0(0)$ \\
\hline
\end{tabular}

${ }^{\mathrm{a} O n e}$ legitimate pharmacy required an account to gain access to services. Overall, 5 internet pharmacies selling Humalog or NovoLog insulin in the United States were not classified using LegitScript.

\section{Discussion}

\section{Principal Findings}

Our analysis demonstrates that both Humalog and NovoLog insulin are readily available from internet pharmacies that engage in illegal sales of prescription drugs. Illegitimate internet pharmacies were found to be abundant using common search engines, outnumbering legitimate internet pharmacies. Of the internet pharmacies included in our analysis, nearly 60\% (29/49) were illegitimate, whereas only $14 \%$ (7/49) were legitimate (with the remainder unclassified). The widespread availability of illegitimate internet pharmacies poses a threat to unsuspecting consumers and provides easy access to those seeking insulin without a prescription [9]. Incentives to purchase insulin from illegitimate internet pharmacies go beyond ease of access, as our analysis reveals that these internet pharmacies offer substantial price reductions as compared with brick-and-mortar stores and legitimate internet pharmacies.

\section{Rising Insulin Costs}

In the United States, rising list prices on rapid-acting insulin analogs such as Humalog and NovoLog insulin have resulted in a substantial cost burden for patients with diabetes. Legislative initiatives to curb insulin costs include, among others, setting out-of-pocket maximums and allowing personal drug importation. However, these reforms have only been trialed in some states, and the legality of the personal importation of insulin remains contentious [28,29]. In 2018, in the midst of public outcry at high insulin costs, the manufacturer Eli Lilly introduced Lispro, an authorized generic to Humalog, at a 50\% discount on the Humalog list price [30]. Unfortunately, according to a Senate report, the uptake of Lispro has been meager at best, with $83 \%$ of 386 surveyed national pharmacies not having Lispro in stock and $69 \%$ unable to order the medication [31]. In 2020, the Trump Administration announced that Medicare would begin offering 1750 different insurance plans that capped out-of-pocket spending to US \$35 for insulin [32]. However, this out-of-pocket maximum is limited only to Medicare beneficiaries. Given the relatively limited action from the federal government, manufacturers, and other key players in the United States pharmaceutical supply chain, high insulin list prices and out-of-pocket costs for many persist. Many patients continue to face insulin access problems, particularly those who are uninsured, which in 2018 accounted for $8.5 \%$ of the US population $[3,33]$.

With financial pressure, some patients who need insulin to manage their diabetes have resorted to illegal activities such as borrowing insulin, importing insulin from lower-cost countries, or purchasing insulin from illegitimate internet pharmacies [8]. Our analysis, which focuses on the internet pharmacy marketplace, demonstrates that among pharmacies that ship within the United States, the per mL cost of Humalog and NovoLog insulin from illegitimate internet pharmacies was approximately 2 to 5 times cheaper than that offered by legitimate internet pharmacies or GoodRx. Such substantial price differences raise concerns that illegitimate internet pharmacies may appeal to patients priced out of traditional means of acquiring insulin. Beyond offering lower prices, rogue internet pharmacies do not require prescriptions and also use marketing methods that appeal to cost-conscious consumers, such as offering bulk discounts or coupons. In addition, illegitimate pharmacies appeal to affordability through language on their homepages.

Although costs are lower for Humalog and NovoLog insulin from illegitimate internet pharmacies, they remain illegal because of the serious risks associated with their use. Humalog and NovoLog insulin are high-risk medications that require both therapeutic monitoring to ensure optimal short- and long-term outcomes and sufficient counseling for the prevention of adverse events such as hypoglycemia. Between 2007 and 2009, nearly $20 \%$ of emergency hospitalizations for the treatment of emergent adverse events were because of insulin [34]. The costs of these visits are not trivial; in 2016, the total average cost per person per visit for hypoglycemia was US $\$ 1965$ for an emergency department visit and US \$11,632 for inpatient hospitalization in the United States [35]. The American Diabetes Association recommends that patients treated with insulin who are unaware of hypoglycemia should be counseled on signs and methods to treat it [36]. 


\section{Threat of Illegitimate Internet Pharmacies}

Our analysis demonstrates that illegitimate internet pharmacies, particularly rogue internet pharmacies, do not offer pharmacy services that are on-par with those offered through legitimate internet pharmacies. The majority $(8 / 9,89 \%)$ of rogue internet pharmacies allowed the purchase of Humalog or NovoLog insulin in the United States without a prescription, precluding the involvement of health care professionals in patient care. Further preventing communication with health care professionals, no rogue internet pharmacies made the offer to speak with pharmacists. On illegitimate internet pharmacy websites, patients were often left without medication information and drug-related warnings and precautions. Illegitimate internet pharmacies, with rogue internet pharmacies being the worst offenders, allow patients to access Humalog and NovoLog insulin with minimal information, predisposing these patients to poor diabetes control and potential development of adverse events.

There is also concern as to whether the quality of insulin obtained from illegitimate internet pharmacies is comparable with that obtained from legitimate internet pharmacies. Low costs offered through illegitimate internet pharmacies could suggest less stringent cold chain shipping methods or lower-quality medications. Although our analysis did not collect information on the quality of Humalog and NovoLog insulin obtained from illegitimate internet pharmacies, substandard and falsified medicines are globally prevalent $[12,37]$. Studies have suggested that poor medication quality from illegitimate pharmacies could further increase patient safety at risk [38]. Illegitimate internet pharmacies, as evinced in our analysis of marketing language, often make claims touting the quality of their products. Ironically, this could amplify the risk of consumers inadvertently purchasing low-quality medications. To address these risks, a multifaceted approach is needed to close illegitimate internet pharmacies, develop better search engine filters, raise public awareness of the dangers of illegitimate internet pharmacies, and address high insulin costs.

National organizations are combating the proliferation of illegitimate internet pharmacies. The FDA's BeSafeRx campaign and the Alliance for Safe Online Pharmacies' Buy Safe Rx campaign help consumers identify illegitimate internet pharmacies and recognize their risks $[39,40]$. The NABP helps consumers identify legitimate internet pharmacies through their list of accredited digital pharmacies, as well as with a verification service through which legitimate internet pharmacies receive a dot-pharmacy domain [13]. The Center for Safe Internet Pharmacies also offers a verification service through its initiative Verify Before You Buy (powdered by LegitScript), wherein consumers can search the URL of an internet pharmacy to check its legitimacy [41]. In May 2020, North Carolina's Secretary of State announced a partnership with the Center for Safe Internet Pharmacies to raise consumer awareness [42].

Regulatory and legal actions are ongoing against illegitimate internet pharmacies. Operation Pangea, an effort led by Interpol in conjunction with the FDA and US Department of Justice, has resulted in the removal of thousands of illegitimate internet pharmacies [43]. LegitScript has also collaborated with the FDA to identify and close illegitimate internet pharmacies [44]. However, illegitimate internet pharmacies persist by closing and reopening under new web addresses, requiring continued vigilance by regulatory authorities.

Given that patients with diabetes are frequently counseled on the management of their disease, health care providers such as physicians and pharmacists are uniquely positioned to lead the charge in making consumers aware of the risks of acquiring insulin from illegitimate internet pharmacies.

\section{Limitations}

The limitations of our study include the small sample size and the cross-sectional design. However, our screening methods were consistent with what US consumers purchasing insulin on the internet might experience. An additional limitation is that we did not analyze the quality of products available from internet pharmacies, precluding conclusions pertaining to medication quality. We did not purchase medications from these websites because we questioned the ethical implications of financially supporting the operations of illegitimate internet pharmacies. Our analysis was conducted before the COVID-19 pandemic. We believe our results are even more relevant now as internet purchases have become commonplace in the United States [45]. Finally, we were unable to quantify the purchase volume of Humalog or NovoLog insulin from these internet pharmacies. The nonspecific, surrogate measure of unique monthly visits is representative of the overall traffic to these websites and is not necessarily indicative of interest in or purchases of Humalog or NovoLog insulin. Despite these limitations, we contend that our analysis reflects the internet pharmacy marketplace for insulin in the United States as accessed through common search engines.

\section{Conclusions}

The relatively low costs of Humalog and NovoLog insulin from easily accessible illegitimate internet pharmacies place patients at risk. Although the elimination of illegitimate internet pharmacies would be the gold standard way to reduce their risk to patients, illegitimate internet pharmacies are elusive. Governmental agencies should continue to pursue legal and regulatory measures with the intent of closing illegitimate internet pharmacies. Search engines should work to filter their results better, decreasing the visibility of illegitimate internet pharmacies. Finally, although public awareness campaigns and provider-to-patient efforts can bring attention to the dangers of illegitimate internet pharmacies, they do not address the reasons that patients may visit these sites. With patient safety in mind, US legislators and members of the pharmaceutical supply chain should work to lower the costs of insulin, thereby diminishing patients' incentive to purchase from illegitimate internet pharmacies. 


\section{Acknowledgments}

This research did not receive any specific grant from funding agencies in the public, commercial, or not-for-profit sectors.

The authors thank the directors and coordinators of the Research and Scholarship in Pharmacy (RASP) pathway at the UNC Eshelman School of Pharmacy for their guidance and support. The authors also thank Colleen Higgins on the Global Health Economics for Pharmacy (GHEP) team for her contributions.

\section{Authors' Contributions}

BP was involved in the methodology, investigation, data curation, and writing of the original draft; LM was associated with methodology and writing, reviewing, and editing; HHC was involved with methodology, writing, reviewing, and editing; SE was involved with methodology, writing, reviewing, and editing; SO was associated with conceptualization, methodology, supervision, writing, reviewing, and editing.

\section{Conflicts of Interest}

None declared.

\section{References}

1. Statistics about diabetes. American Diabetes Association. 2018. URL: https://www.diabetes.org/resources/statistics/ statistics-about-diabetes [accessed 2021-12-20]

2. Complications. American Diabetes Association. 2021. URL: https://www.diabetes.org/diabetes/complications [accessed 2021-12-20]

3. Cefalu WT, Dawes DE, Gavlak G, Goldman D, Herman WH, Van Nuys K, Insulin AccessAffordability Working Group. Insulin access and affordability working group: conclusions and recommendations. Diabetes Care 2018 Jun;41(6):1299-1311. [doi: 10.2337/dci18-0019] [Medline: 29739814]

4. Dave CV, Hartzema A, Kesselheim AS. Prices of generic drugs associated with numbers of manufacturers. N Engl J Med 2017 Dec 28;377(26):2597-2598. [doi: 10.1056/NEJMc1711899] [Medline: 29281576]

5. Bell J. Lilly reveals Humalog pricing details amid larger scrutiny over insulin costs. BioPharma Dive. 2019. URL: $\underline{\text { https:/ }}$ /www.biopharmadive.com/news/lilly-humalog-price-list-net-insulin/551236/ [accessed 2021-12-20]

6. Herkert D, Vijayakumar P, Luo J, Schwartz JI, Rabin TL, DeFilippo E, et al. Cost-related insulin underuse among patients with diabetes. JAMA Intern Med 2019 Jan 01;179(1):112-114 [FREE Full text] [doi: 10.1001/jamainternmed.2018.5008] [Medline: 30508012]

7. Costs and rationing of insulin and diabetes supplies: findings from the 2018 T1International Patient Survey. T1International. 2018. URL: https://www.tlinternational.com/media/assets/file/

T1International Report - Costs and Rationing of Insulin Diabetes Supplies 2.pdf [accessed 2021-11-22]

8. Litchman ML, Oser TK, Wawrzynski SE, Walker HR, Oser S. The underground exchange of diabetes medications and supplies: donating, trading, and borrowing, oh my!. J Diabetes Sci Technol 2019 Dec 04:1932296819888215 [FREE Full text] [doi: 10.1177/1932296819888215] [Medline: $\underline{\text { 31801370] }}$

9. Lovett KM, Liang BA, Mackey TK. Online, direct-to-consumer access to insulin: patient safety considerations and reform. J Diabetes Sci Technol 2012 Nov 01;6(6):1503-1506. [doi: 10.1177/193229681200600632] [Medline: 23294798]

10. The internet pharmacy market in 2016. LegitScript for Center for Safe Internet Pharmacies. 2016. URL: https:/ /safemedsonline.org/wp-content/uploads/2016/01/The-Internet-Pharmacy-Market-in-2016.pdf [accessed 2021-12-20]

11. Mackey TK, Nayyar G. Digital danger: a review of the global public health, patient safety and cybersecurity threats posed by illicit online pharmacies. Br Med Bull 2016 Jun;118(1):110-126 [FREE Full text] [doi: 10.1093/bmb/ldw016] [Medline: 27151957]

12. WHO Global Observatory for eHealth. Safety and Security on the Internet: Challenges and Advances in Member States : Based on the Findings of the Second Global Survey on eHealth. Geneva: World Health Organization; 2011:1-86.

13. Digital pharmacy accreditation criteria. National Association of Boards of Pharmacy. URL: https://nabp.pharmacy/programs/ digital-pharmacy/ [accessed 2021-12-20]

14. Veronin MA, Clancy KM. Attrition of Canadian Internet pharmacy websites: what are the implications? Drug Healthc Patient Saf 2013;5:171-179 [FREE Full text] [doi: 10.2147/DHPS.S46232] [Medline: 23983491]

15. Penley B, Chen H, Eckel SF, Ozawa S. Characteristics of online pharmacies selling Adderall. J Am Pharm Assoc (2003) 2021;61(1):103-109 [FREE Full text] [doi: 10.1016/j.japh.2020.07.022] [Medline: 32912756]

16. Alwon BM, Solomon G, Hussain F, Wright DJ. A detailed analysis of online pharmacy characteristics to inform safe usage by patients. Int J Clin Pharm 2015 Feb;37(1):148-158. [doi: 10.1007/s11096-014-0056-1] [Medline: 25564180]

17. Akinbosoye OE, Taitel MS, Grana J, Hill J, Wade RL. Improving medication adherence and health care outcomes in a commercial population through a community pharmacy. Popul Health Manag 2016 Dec;19(6):454-461 [FREE Full text] [doi: 10.1089/pop.2015.0176] [Medline: 27035728] 
18. Cicero TJ, Ellis MS. Health outcomes in patients using no-prescription online pharmacies to purchase prescription drugs. J Med Internet Res 2012 Dec 06;14(6):e174 [FREE Full text] [doi: 10.2196/jmir.2236] [Medline: 23220405]

19. LegitScript merchant and website classification guide. LegitScript. URL: https://www.legitscript.com/classifications-guide/ [accessed 2021-12-20]

20. Official measure of the digital world. SimilarWeb. URL: https://www.similarweb.com/ [accessed 2021-12-20]

21. Identify geographical location and proxy by IP address. IP2Location. URL: https://www.ip2location.com/ [accessed 2021-12-20]

22. Orizio G, Rubinelli S, Schulz PJ, Domenighini S, Bressanelli M, Caimi L, et al. "Save 30\% if you buy today". Online pharmacies and the enhancement of peripheral thinking in consumers. Pharmacoepidemiol Drug Saf 2010 Sep;19(9):970-976. [doi: 10.1002/pds.2007] [Medline: 20652863]

23. Gelatti U, Pedrazzani R, Marcantoni C, Mascaretti S, Repice C, Filippucci L, et al. 'You've got m@il: fluoxetine coming soon!': accessibility and quality of a prescription drug sold on the web. Int J Drug Policy 2013 Sep;24(5):392-401. [doi: 10.1016/j.drugpo.2013.01.006] [Medline: 23433969]

24. Prescription savings you can trust. PharmacyChecker. URL: https://www.pharmacychecker.com [accessed 2021-12-20]

25. HealthWarehouse. URL: https://www.healthwarehouse.com/ [accessed 2021-12-20]

26. CVS Pharmacy. URL: https://www.cvs.com/ [accessed 2021-12-20]

27. Prescription same-day home delivery on the Costco app. Costco Pharmacy. URL: https://costco.mobilepharmacyhelp.com/ same-day-delivery [accessed 2021-12-20]

28. Findlay S. States pass record number of laws to reel in drug prices. Kaiser Health News. 2019. URL: https://khn.org/news/ states-pass-record-number-of-laws-to-reel-in-drug-prices/ [accessed 2021-12-20]

29. Personal importation. US Food \& Drug Administration. 2018. URL: https://www.fda.gov/industry/import-basics/ personal-importation [accessed 2021-12-20]

30. Lilly to introduce lower-priced insulin. Eli Lilly and Company. 2019. URL: https://www.prnewswire.com/news-releases/ lilly-to-introduce-lower-priced-insulin-300805560.html [accessed 2021-11-23]

31. Inaccessible insulin: the broken promise of Eli Lilly's authorized generic. Prepared by the Offices of U.S. Senator Elizabeth Warren and U.S. Senator Richard Blumenthal. 2019. URL: https://www.warren.senate.gov/imo/media/doc/ Inaccessible\%20Insulin\%20report.pdf [accessed 2021-11-23]

32. President Trump announces lower out of pocket insulin costs for Medicare's seniors. Centers for Medicare \& Medicaid Services. 2020. URL: https://www.cms.gov/newsroom/press-releases/ president-trump-announces-lower-out-pocket-insulin-costs-medicares-seniors [accessed 2021-11-23]

33. Berchick E, Barnett J, Upton R. Health insurance coverage in the United States. In: Kinney ED, editor. Protecting American Health Care Consumers. Durham, North Carolina: Duke University Press; 2019.

34. Budnitz DS, Lovegrove MC, Shehab N, Richards CL. Emergency hospitalizations for adverse drug events in older Americans. N Engl J Med 2011 Nov 24;365(21):2002-2012. [doi: 10.1056/NEJMsa1103053] [Medline: 22111719]

35. Basu S, Berkowitz SA, Seligman H. The monthly cycle of hypoglycemia: an observational claims-based study of emergency room visits, hospital admissions, and costs in a commercially insured population. Med Care 2017 Jul;55(7):639-645 [FREE Full text] [doi: 10.1097/MLR.0000000000000728] [Medline: 28481762]

36. American Diabetes Association. 3. Comprehensive medical evaluation and assessment of comorbidities: standards of medical care in diabetes-2018. Diabetes Care 2018 Dec;41(Suppl 1):28-37. [doi: 10.2337/dc18-S003] [Medline: 29222374]

37. Ozawa S, Evans DR, Bessias S, Haynie DG, Yemeke TT, Laing SK, et al. Prevalence and estimated economic burden of substandard and falsified medicines in low- and middle-income countries: a systematic review and meta-analysis. JAMA Netw Open 2018 Aug 03;1(4):e181662 [FREE Full text] [doi: 10.1001/jamanetworkopen.2018.1662] [Medline: 30646106]

38. Orizio G, Merla A, Schulz PJ, Gelatti U. Quality of online pharmacies and websites selling prescription drugs: a systematic review. J Med Internet Res 2011 Sep 30;13(3):e74 [FREE Full text] [doi: 10.2196/jmir.1795] [Medline: 21965220]

39. BeSafeRx: Your source for online pharmacy information. US Food \& Drug Administration. 2016. URL: https://www. fda.gov/drugs/quick-tips-buying-medicines-over-internet/besaferx-know-your-online-pharmacy [accessed 2021-12-20]

40. Alliance for safe online pharmacies. ASOP Global. URL: https://buysaferx.pharmacy/ [accessed 2021-12-20]

41. Verify before you buy. Center for Safe Internet Pharmacies (CSIP). URL: https://verifybeforeyoubuy.org/ [accessed 2021-12-20]

42. Schlosser A, Crowley T. North Carolina Secretary of State partners with CSIP to promote online pharmacy verification. The Center for Safe Internet Pharmacies (CSIP). URL: https://safemedsonline.org/2020/05/ north-carolina-secretary-of-state-partners-with-csip-to-promote-online-pharmacy-verification/ [accessed 2021-12-20]

43. Operation Pangea - shining a light on pharmaceutical crime. Interpol. 2019. URL: https://www.interpol.int/en/ News-and-Events/News/2019/Operation-Pangea-shining-a-light-on-pharmaceutical-crime [accessed 2021-12-20]

44. LegitScript helps shut down 6,149 rogue internet pharmacies in 2019. LegitScript. 2020. URL: https://www.legitscript.com/ blog/2020/01/legitscript-helps-shut-down-6149-rogue-internet-pharmacies-in-2019/ [accessed 2021-12-20]

45. Charm T, Coggins B, Robinson K, Wilkie J. The great consumer shift: Ten charts that show how US shopping behavior is changing. McKinsey \& Company 2020:1-13 [FREE Full text] 


\section{Abbreviations}

FDA: Food and Drug Administration

NABP: National Association of Boards of Pharmacy

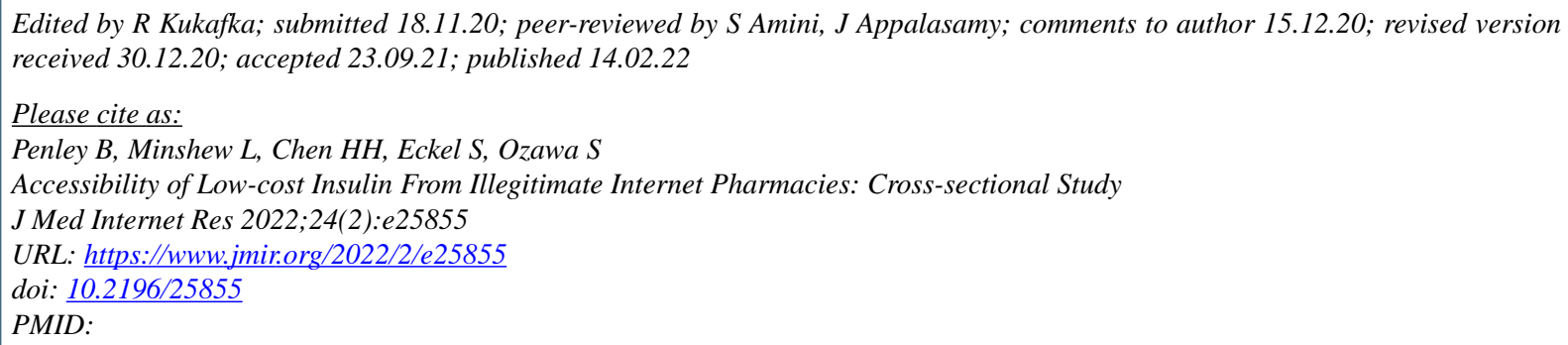

CBenjamin Penley, Lana Minshew, Hui-Han Chen, Stephen Eckel, Sachiko Ozawa. Originally published in the Journal of Medical Internet Research (https://www.jmir.org), 14.02.2022. This is an open-access article distributed under the terms of the Creative Commons Attribution License (https://creativecommons.org/licenses/by/4.0/), which permits unrestricted use, distribution, and reproduction in any medium, provided the original work, first published in the Journal of Medical Internet Research, is properly cited. The complete bibliographic information, a link to the original publication on https://www.jmir.org/, as well as this copyright and license information must be included. 